\title{
"AS PROFESSORAS FALAM QUE EU SOU LENTA": O AUTOCONCEITO NA INTERFACE EDUCAÇÃO E SAÚDE
}

\section{Mariana Inés Garbarino}

Universidade de São Paulo
Recebido em: 31/05/2019

1a revisão em: 18/08/2019

Aceito em: 29/10/2019

\section{RESUMO}

Durante a infância a escola constitui o principal espaço social onde as habilidades e limitações individuais ficam publicamente expostas. O estigma do "déficit escolar" leva a sentimentos de fracasso, incapacidade, e a um autoconceito empobrecido. Considerando a importância dos colegas e dos educadores nesse processo de co-construção, o estudo visou indagar o papel dessas relações interpessoais em crianças com queixa escolar no contexto de um atendimento clínico. Foram analisados, qualitativamente, registros de rodas de conversa e questionários de anamnese. Os resultados evidenciaram que para as crianças resultam significativas as provocações e zoações dos pares referentes a características físicas ou da personalidade. O olhar dos educadores expressou-se em atributos e elogios sobre o desempenho acadêmico. Ambos os olhares apresentaram tonalizações de gênero. Verificou-se, ademais, a fecundidade das rodas de conversa como um dispositivo metodológico e de intervenção favorável à tomada de consciência do autoconceito e dos sentimentos atrelados à autopercepção.

Palavras-chave: autoconceito; queixa escolar; rodas de conversa. 


\title{
"THE TEACHERS SAY THAT I AM SLOW": THE SELF-CONCEPT IN THE EDUCATION AND HEALTH INTERFACE
}

\begin{abstract}
During childhood the school is the main social space where individual skills and limitations are publicly exposed. The stigma of "school deficit" leads to feelings of failure, incapacity, and impoverished self-concept. Considering the importance of colleagues and educators in this process of co-construction, the study aimed to investigate the role of these interpersonal relationships in children with a school complaint in the context of clinical care. Records of conversation circles and anamnesis questionnaires were qualitatively analyzed. The results showed that for children, the provocations and motions of the pairs regarding physical or personality characteristics are significant. The gaze of educators expressed themselves in attributes and praises about academic performance. Both regards presented gender shades. The fertility of the conversation circles was also verified as a methodological and intervention device favorable to the awareness of selfconcept and feelings linked to self-perception.
\end{abstract}

Keywords: self-concept; school complaint; conversation circles. 


\section{“LAS PROFESORAS DICEN QUE SOY LENTA": EL AUTOCONCEPTO EN LA INTERFASE EDUCACIÓN Y SALUD}

\section{RESUMEN}

Durante la infancia la escuela constituye el principal espacio social donde las habilidades y limitaciones individuales quedan públicamente expuestas. El estigma del "déficit escolar" lleva a sentimientos de fracaso, incapacidad, y a un autoconcepto empobrecido. Considerando la importancia de los colegas y de los educadores en ese proceso de co-construcción, el estudio indaga el papel de esas relaciones interpersonales en niños con queja escolar en el contexto de una atención clínica. Se analizaron, cualitativamente, registros de ruedas de conversación y cuestionarios de anamnesis. Los resultados evidenciaron que para los niños resultan significativas las provocaciones y burlas de los pares referentes a características físicas o de la personalidad. La mirada de los educadores se expresó en atributos y elogios sobre el desempeño académico. Ambas perspectivas presentaron tonalizaciones de género. Se verificó, además, la fecundidad de las ruedas de conversación como un dispositivo metodológico y de intervención favorable a la toma de conciencia del autoconcepto y de los sentimientos ligados a la autopercepción.

Palabras clave: autoconcepto; queja escolar; ruedas de conversación. 


\section{INTRODUÇÃO}

"Ir mal na escola" pode resultar em uma das primeiras feridas narcisistas e marcas sociais de exclusão. Durante a infância a escola constitui o principal espaço social onde as habilidades e limitações individuais ficam publicamente expostas (Schlemenson, 2009; Urribarri, 2012). Atualmente as dificuldades de aprendizagem são crescentemente abordadas no contexto das pesquisas em Psicologia e também em outros campos do saber como Medicina, Educação, Psicopedagogia e Sociologia. A complexidade do objeto leva a verificar vários focos de análise sociais, históricos e afetivos para além dos cognitivos, dentre os quais podem se destacar: o fracasso escolar em termos de políticas públicas (Alves \& Soares, 2013) e do histórico processo de exclusão dos alunos oriundos de famílias com baixos recursos (Paula \& Tfouni, 2009; Patto, 1997); as conceições dos pais acerca do "não aprender" (Borlido \& Martins, 2011); as influências do contexto familiar (Antunes \& Falcke, 2010); e suas relações com o autoconceito e a autoestima (Monteiro 2012; Muniz \& Fernandes, 2016; Stevanato et al., 2003).

Entretanto, tal como assinalado por vários autores (Bzuneck \& Sales, 2011; Muniz \& Fernandes, 2016; Polydoro \& Azzi, 2008), no contexto brasileiro faltam ainda pesquisas sobre as relações interpessoais na sala de aula e acerca de estratégias de regulação afetiva e intervenções que promovam a consciência e percepção das emoções. Considerando esses apontamentos, o presente trabalho pretende contribuir apresentando uma articulação teórico-clínica com base no estudo da co-construção autoconceito no contexto das relações interpessoais com pares e educadores de crianças com queixa escolar participantes de um programa de intervenção grupal realizado como atividade de extensão universitária.

\section{O QUE APRENDEM AS CRIANÇAS QUE “NÃO APRENDEM"?}

Se a aprendizagem e o desenvolvimento infantil são processos intimamente relacionados (Golse, 2009; Macedo, Petty, \& Passos, 2005), as dificuldades escolares estão atreladas a percursos de desenvolvimento restringidos. A expressão "crianças que não aprendem" costuma se referir às crianças com desempenho escolar abaixo do esperado. Entretanto, mesmo sem aprender os conteúdos exigidos em matemática ou português, na escola elas não deixam de aprender modos de se relacionar com os outros, de se defender ou se submeter a situações de exposição e a desenvolver formas mais ou menos sofisticadas de ocultar suas dificuldades ou deixá-las passar despercebidas (Garbarino, 2017; Golse, 2009; Schlemenson, 2009).

O processo de escolarização alimenta o sofrimento psíquico quando há cronicidade no estigma do "déficit", rótulo que leva a sentimentos de inferioridade, incapacidade e menos-valia (Cabanach \& Arias, 1998). Estes alunos manifestam sentimentos de fracasso e uma autoimagem depreciativa de si mesmos (Carneiro, Martinelli \& Sisto, 2003; Jacob, Loureiro, Marturano, Linhares, 
\& Machado, 1999; Osti \& Brenelli, 2013). A correlação entre autoconceito e desempenho dos alunos é diretamente proporcional (Sisto \& Martinelli, 2006). Conforme aumenta a dificuldade de aprendizagem, diminuem os sentimentos positivos, as crenças sobre a própria competência, a persistência diante das tarefas e as expectativas de êxito dos alunos. Diversas pesquisas corroboram a existência de uma correlação altamente significativa entre essas variáveis (Cabanach \& Arias 1998; Carneiro et al., 2003; Muniz \& Fernandes, 2016).

O autoconceito define-se como a representação do si mesmo que se estrutura, por um lado, em vivências e interações com os outros e, por outro, no valor que se adjudica às próprias condutas (Sisto \& Martinelli, 2006). Nesse sentido, conforme Muniz e Fernandes (2016), a aprendizagem escolar depende das relações das crianças com pares e professores, sendo que as variáveis socioafetivas interferem no desempenho acadêmico. Estudos mostraram que alunos do Ensino Fundamental I com rebaixamento no autoconceito escolar tendem a se sentir não só menos hábeis para as tarefas escolares, mas também mais rejeitados pelos pares. Ansiedade e autoconceito apresentam correlações negativas significativas, ou seja, crianças que não manifestam uma percepção positiva sobre si mesmas tendem expressar maiores escores de ansiedade escolar (Muniz \& Fernandes, 2016).

Contudo, a relação entre dificuldades de aprendizagem e autoconceito escolar não pode ser estabelecida na forma de causalidade. Não se sabe em que medida as experiências de fracasso escolar contribuem para a formação de um autoconceito escolar negativo, ou se a existência de um conceito de si mesmo mais negativo contribui para a configuração de situações de fracasso escolar (Cabanach \& Arias, 1998). Em pesquisa sobre aspectos afetivos e cognitivos no desempenho com jogos lógico-matemáticos também verificou-se que as relações entre regulações afetivas, como a autovalorização, e cognitivas, como o interesse e a memória, são diversas em cada sujeito não sendo possível concluir uma relação padronizada (Santos \& Ortega, 2012). Entretanto, pode-se afirmar que "crianças que apresentam dificuldades de aprendizagem tendem a ter um autoconceito escolar mais rebaixado do que crianças que não têm a dificuldade" (Carneiro et al., 2003, p. 433), o que leva a postular que o mais provável é que estes fatores estejam imbricados numa relação de mútua causalidade.

Dentre os fatores de risco para as dificuldades de aprendizagem, encontram-se o maltrato, a rigidez, o autoritarismo, o excesso de crítica, a hipoestimulação no lar e a frequente mudança de professores (Sabina, Saéz \& Roméu, 2010). Ademais, essas questões constituem um fator de risco para problemas psicossociais. Entretanto, a carência de estudos longitudinais impede de se identificar quais fatores de risco são desencadeantes, intensificadores ou consequências das dificuldades de aprendizagem. Na literatura, por exemplo, o déficit de habilidades sociais aparece tanto no lugar de causa como consequência (Mazer, Bello \& Bazon, 2009). Além disso, a cronicidade dessas limitações pode se agravar no 
atual contexto do fenômeno de bullying escolar e cyberbullying (Zequinão, Medeiros, Pereira, \& Cardoso, 2016).

Nesse sentido, as dificuldades escolares provocam nas crianças sentimentos de fracasso e incompetência não só para a aprendizagem, mas também no escopo pessoal causando estresse e mal estar. Pesquisas mostram que o rendimento escolar é a dimensão mais destacada em termos de qualidade de vida infantil (Fialho, Santana, \& Bradenburg, 2015). Portanto, melhoras nas interações cognitivas e socioafetivas do contexto escolar permitem uma mudança global no desenvolvimento infantil, com implicações relevantes para a qualidade de vida dos alunos e educadores envolvidos. O fracasso escolar não é um fenômeno individual que impacta unicamente nas crianças, mas que leva a sentimentos de insucesso coletivo que se estendem para suas famílias e professores. Nesse ângulo holístico do processo de aprender, cabe considerar o sujeito que aprende na conjuntura de um momento histórico, de uma etapa do desenvolvimento da inteligência e da afetividade e de um conjunto de crenças, saberes e práxis dos educadores (Paín, 2010).

Pesquisas sobre aspectos afetivos dos processos de ensino e aprendizagem apontam ao papel do professor como um fator obstaculizador ou facilitador (Ribeiro, 2010; Muniz \& Fernandes, 2016). Os resultados obtidos por Osti e Brenelli (2013) mostram que alunos com dificuldades de aprendizagem têm uma representação negativa de si mesmos e nutrem baixas expectativas sobre seu desempenho escolar, vivenciando este como uma experiência tensa. A representação negativa dos alunos pode ter por base o discurso de seu professor. As autoras expõem que parte das crianças entrevistadas considera que suas professoras entendem que suas dificuldades de aprendizagem provêm de alguma doença na cabeça, de um problema no cérebro, ou que são consequência de uma "cabeça que não funciona direito", o que foi expresso em frases como: "a prô diz que eu tenho problema no cérebro e que não aprendo" (Osti \& Brenelli, 2013, p. 420).

As crenças sobre as competências que o aluno acredita possuir em relação a seu desempenho acadêmico são construídas, por um lado, com base nas experiências de sucesso ou fracasso vivenciadas na instituição escolar, e por outro, nas avaliações que recebe de seus professores, colegas e familiares. A complexidade dessa gênese é atualmente reforçada pelo fenômeno do bullying escolar, definido como uma dinâmica que envolve a todos os atores escolares na sua origem, manutenção e/ou interrupção. Além dos agressores e suas vítimas, os espectadores possuem um lugar privilegiado no reforço positivo ou negativo da agressão (Zequinão et al., 2016).

A co-construção das representações valorativas da criança sobre o si mesmo constitui, assim, um processo lento que se desenvolve nas experiências e relações com os outros que aprovam ou desaprovam seu comportamento. Esses "outros" são, principalmente, os adultos cuidadores significativos que exercem algum 
controle sobre a criança e cujas opiniões têm influência sobre ela (Osti \& Brenelli, 2013; Sadalla, 1998). Entretanto, também o juízo dos colegas tem um papel protagonístico nessa psicogênese considerando a tendência das crianças entre 7 e 11 anos à autorrealização e satisfação na vida de grupo, ou seja, a vida similar para todos, baseada no "querer ser" como os outros (Arbisio, 2007; Urribarri, 2012). No caso dos colegas, durante esse período da infância eles instauram o sentimento de pertencimento, compartilhando modalidades de ação, ideais e desenvolvendo identificações grupais (Urribarri, 2012). Essa dinâmica se organiza também na demarcação de diferenças de gênero na amizade, que leva a relações grupais que fortalecem a divisão estereotipada da imposição de beleza feminina e de força física masculina (Arbisio, 2007).

O levantamento de Bzuneck e Sales (2011) também confirmou que os alunos com dificuldade escolar dão especial importância à interpretação dos professores e colegas sobre seu desempenho. Ademais, mostrou que em alguns casos os alunos preferem ser vistos como preguiçosos mais do que como incapazes e, em outros, optam por gerar compaixão, expressando empenho para deixar claro que a causa do fracasso deve-se a incapacidade.

O contexto da dificuldade escolar costuma restringir o investimento afetivo tanto de educadores, escola e pares (Rosenthal, 1974). Nesse caso, o funcionamento do Eu infantil é autopercebido como insuficiente para cumprir com as expectativas de pais e professores, para se sentir competente diante do grupo de pares e também diante de si mesmo no papel de "ser aluno" na instituição exogâmica mais importante desse período. A teoria do ciclo vital de Erikson realizou contribuições para pensar a escola como favorecedora ou restritiva do "sentimento de ser capaz de produzir", fundamental para conquistar a consideração e admiração dos outros (Bordignon, 2007). Na escola exige-se a produtividade e competência da criança, configurando um lugar de expectativas e exigências no qual o aluno vivencia sentimentos de ajuste ou desajuste e Erikson denominou "produtividade vs. inferioridade" ao período de crises que pode atravessar a criança em idade escolar. O sentimento de inadequação e inferioridade é experimentado quando ela não consegue se autoavaliar como produtiva para cumprir com o que acredita que esperam dela socialmente. A interpretação de (in)competência, a visão negativa da capacidade de aprender e o sentimento de desvalia sobre si mesma podem levar a criança a evitar situações sociais ou de competição nas quais fique em evidência (Bordignon, 2007).

Atualmente há ainda poucos estudos sobre as relações interpessoais no contexto escolar (Bzuneck \& Sales, 2011; Shure, 2006) e aponta-se a necessidade de trabalhos que incorporem estratégias de regulação afetiva, intervenções que promovam a consciência e percepção das emoções (Polydoro \& Azzi, 2008), assim como programas de intervenção para melhorar o autoconceito e diminuir a ansiedade escolar (Muniz \& Fernandes, 2016). Nesse sentido, e considerando a importância dos colegas (Arbisio, 2007; Urribarri, 2012; Zequinão et al., 2016) e dos educadores (Bzuneck e Sales; 2011; Osti \& Brenelli, 2013; Sabina et al., 2010; 
Sadalla, 1998) no processo contínuo de co-construção do autoconceito, o presente trabalho pretende contribuir no preenchimento dessa lacuna.

Nesse intuito, a pesquisa indaga as relações interpessoais com pares e educadores em um contexto de atendimento clínico para crianças com queixa escolar. Considerando a primacia dos estudos da teoria social cognitiva, essas relações são analisadas discutindo sua conformação desde um prisma conceitual menos habitual baseado em contribuições de autores contemporâneos da psicologia genética e da psicanálise. Além disso, o trabalho sublinha a fecundidade das rodas de conversa como um dispositivo de intervenção favorável à tomada de consciência do autoconceito e dos sentimentos atrelados a autopercepção do si mesmo diante do olhar de pares e adultos.

\section{MÉTODO}

A pesquisa foi realizada no contexto de um programa de extensão universitário que, realiza intervenções para crianças com queixa escolar. A primeira parte das sessões consiste em propostas de produção escrita, gráfica e na resolução de jogos lógico-matemáticos. A segunda estrutura-se no dispositivo de rodas de conversa sobre temáticas diversas relacionadas ao âmbito escolar e familiar.

\section{PARTICIPANTES}

Os participantes têm entre 7 e 11 anos. Eles frequentam, majoritariamente, escolas públicas ou fundações. O atendimento é grupal, conformado geralmente por 8 a 10 crianças, com duração de três semestres e encontros semanais de uma hora. A demanda com que chegam aos atendimentos é diversificada conforme a prevalência de dificuldades na alfabetização e/ou matemática, queixas por dispersão, falta de interesse, desatenção, problemas de relacionamento e disciplina, e diagnósticos de transtornos específicos ou síndromes (suspeita ou diagnóstico de TDAH, dislexia, etc.). A pesquisa foi submetida e aprovada pelo Comitê de Ética em Pesquisa com Seres Humanos (CEPH) da Universidade de São Paulo, conforme parecer número 1.082.789. Para manter o anonimato, os participantes $(P)$ foram identificados com um número e o sexo entre parêntese.

\section{INSTRUMENTOS}

Foram utilizados registros escritos das rodas de conversa e questionários de anamnese preenchidos pelos familiares das crianças. As rodas de conversa constituem uma metodologia amplamente utilizada com adolescentes e adultos no âmbito da saúde (Branco \& Pan, 2016; Melo et al., 2016; Sampaio, Santos, Agostini, \& Salvador, 2014), mas os estudos com crianças no âmbito escolar e clínico ainda são escassos. Seu potencial como dispositivo de intervenção radica em possibilitar que a criança, usufruindo do espaço de circulação da palavra, vivencie um novo modo de autovalorização como sujeito crítico pensante em 
uma posição mais autônoma, descentrada e flexível com os objetos de conhecimento e nas suas relações interpessoais no contexto escolar e familiar.

\section{PROCEDIMENTOS}

Para a coleta de dados foram consultados arquivos de materiais das crianças participantes e de suas famílias. Os materiais das crianças consistem em registros escritos das rodas de conversa; os materiais dos familiares são conformados pelas produções escritas das anamneses realizadas na inscrição. No total, foram analisados 10 registros de rodas de conversa e 24 questionários de anamnese referentes a sete semestres, do período 2011-2014, em que a pesquisadora foi membro da equipe. $O$ recorte do material foi realizado selecionando as temáticas relacionadas à autovalorização no contexto do relacionamento com pares e das produções discursivas dos educadores.

Os dados foram abordados qualitativamente, conforme a análise de conteúdo (Castro, Abs, \& Sarriera, 2011). Com base nos seus lineamentos foi realizada a leitura sistemática e minuciosa do material para identificar os temas convergentes focalizando os principais qualificadores e descritores escolhidos pelos participantes. A seguir, os resultados exemplificam aqueles significados e atribuições causais que circularam com maior frequência em suas produções discursivas sistematizados em dois eixos: o olhar dos pares e dos educadores.

\section{RESULTADOS}

\section{O OlHAR dos pares}

Para indagar de que maneira as crianças eram avaliadas pelos colegas e identificar possíveis sentimentos negativos por motivos de "zoação", foram questionadas as provocações que resultavam mais significativas. O disparador foi a pergunta [Já zoaram com você ou te disseram um apelido que você não gostou?]. A leitura das respostas levou à confecção de cinco categorias apresentadas e exemplificadas na Tabela 1, segundo a apelação a: (1) características físicas; (2) atributos da personalidade; (3) negação do conflito em si mesmo e menção de colegas que sofreram com isso; (4) diminutivos ou deformação do nome; (5) sem especificação.

Conforme a Tabela 1 observa-se que as provocações mencionadas são diversas, desde apelidos aparentemente inofensivos, como os diminutivos, aos mais violentos, físicos ou de índole racista. O exemplo de $M(M)$ aponta uma agressão referida a sua qualidade como sujeito pensante e, os de $\mathrm{Ed}(\mathrm{M})$ e Th (M) dão indícios de um movimento de descentração e reciprocidade admitindo que também provocam os outros. Também o xingamento ou críticas aos próprios pais dinamiza fortes sentimentos de angústia para as crianças, tal como ficou ilustrado no seguinte exemplo de outra roda de conversa: [Se você pudesse mudar o 
mundo o que faria?] P (M) diz: "tirar os maus e parar de fazer bullying comigo e xingando minha mãe".

\section{Tabela 1.}

\section{Ilustrações de provocações significativas dos pares de acordo com o conteúdo}

\section{(1) \\ Características \\ físicas}

(2) Atributos da personalidade

(3) Aconteceu
com
outro/nunca
comigo

(4) Diminutivos ou deformação do nome

(5) Inespecíficas
Fe (M) neguinho cinza, Mi (F) Feia, Lu (M) gorducho, gordo tapete velho, Le (F) baleia feia, Ja (F) Bruxa, Félix da novela.

$M(M)$ no segundo ano me falavam que eu era tonto e burro.

$\operatorname{Ar}(\mathrm{M})$ nunca aconteceu comigo, $\mathrm{Cl}(\mathrm{M})$ um moleque chamava outro de zoação, De (M) chamam outro de cabrito, Ca (M) chamam outro pimentinha, Ed (M), não fizeram isso em mim, eu às vezes zôo e falo coisas e os outros também falam.

Ga (M) Bibi, "caminhãozinho da mamãe", La (F) Lala, GuiS (M) falaram um nome que eu não gostei, $\mathrm{Fe}(\mathrm{M})$ apelido ruim, $\mathrm{A}$

(F) me chamaram de Amadeo
Gui Q (M) riram de mim, B (M) sim falaram, Vi (M), me zoaram, Th (M) várias pessoas enchem eu. Eu fico bravo, às vezes eu provoco.

Também a dimensão de gênero permeia a construção do autoconceito com modelos masculinos de força física e femininos relacionados ao "ser bela" via controle do peso e cuidado do corpo, das unhas e do cabelo (Arbisio, 2007; Gutton, 1973/2009) que foram observados em diversos momentos dos atendimentos. Assim como sublinhado na literatura (Souza, 2014; Steibel et al., 2011) é habitual que as meninas cheguem às sessões com as unhas pintadas, usando maquiagem, sapato de salto ou diversos accessórios no cabelo. Fora das rodas de conversa, a imposição do "ser bela" ficou também manifestado na fala de Is (F) quando comenta que pinta as unhas para ir à escola porque "tenho que ir bonita, né?".

Para algumas crianças narrar conflitos escolares resulta difícil. Muitas afirmam não lembrar, não saber responder ou deixam inferir certos traços defensivos para falar de situações que podem recordar angústias. No caso de Be $(F)$, diante da pergunta acerca de conflitos na escola primeiro nega sua existência dizendo que: "não aconteceu nada...", mas posteriormente acrescenta: "acontecem coisas horríveis e violentas" deixando assim evidenciar seus sentimentos na escolha de adjetivos afetivamente intensos.

Fora da roda de conversa também surgem narrativas relacionadas à dimensão especular do outro no juízo do si mesmo. S (F) costuma se mostrar inibida ou pouco envolvida nas suas enunciações da roda, dando respostas rígidas e 
empobrecidas com monossílabos e frases do estilo "sei lá", "não sei" ou já feitas como "respeitar os outros" que não logra desenvolver ou argumentar. Entretanto, em uma ocasião em que não havia nenhuma criança por perto, ela conseguiu tomar uma posição de enunciação contando para a psicóloga do atendimento que na escola sentia vergonha porque os colegas diziam que ela não sabia desenhar.

\section{O OLHAR DOS EDUCADORES}

Para indagar a percepção dos participantes acerca do olhar dos educadores sobre si mesmos e seu desempenho foram analisados: o registro de rodas de conversa e as descrições das anamneses escritas pelos próprios adultos. No contexto das rodas foi selecionada a proposta [Que elogios você costuma receber?]. A partir da leitura dos registros observaram-se três tipos de destaques, tal como apresentado a seguir, na Tabela 2.

Tabela 2.

\section{Ilustrações de elogios identificados pelas crianças}

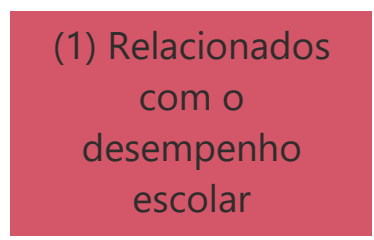

(2) Afetivosendogâmicos relacionados ao ser

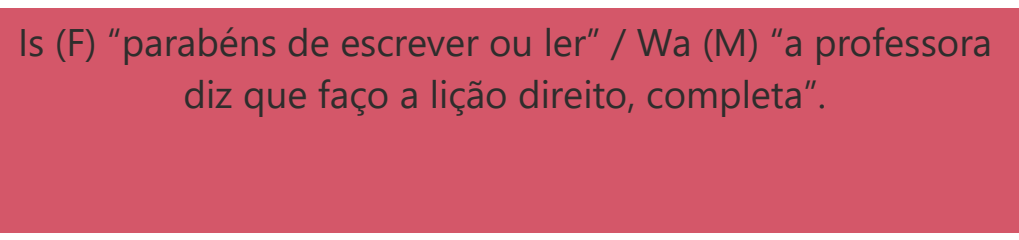

Ra (M) "arrumo a casa e a minha mãe fala que sou bom filho" / Pa (M) "minha mãe fala que sou bonito, o melhor filho do mundo".

\section{(3) Impossibilidade de identificação de elogios}

\section{Jo (M) "não sei" / J (M) [ficou calado, não quis responder]}

Cabe destacar que, para além do conteúdo do elogio, a temática proposta na roda visa identificar se as crianças detectam educadores que olham para eles e apontam conquistas, descobertas ou virtudes, reforçando e aprovando ações e atitudes socialmente esperadas. Nesse sentido, a terceira categoria não necessariamente permite inferir que a criança não costuma receber elogios dos adultos (o que pode ser fato), mas, especialmente, que não consegue lembrá-los ou apropriá-los para si.

Em conformidade com o que já foi explorado na literatura, os elogios que explicitam os próprios pais nos questionários de anamnese visam compensar a ferida narcisista da dificuldade escolar. Eles referem, principalmente, à defesa da capacidade da criança, em frases do estilo "você é inteligente, mas.... não presta atenção, tem preguiça, etc.". Esses elogios constituem interpretações implícitas que a criança recebe em relação à causa da sua dificuldade de aprendizagem. Nesse contexto, dentre os discursos parentais observou-se a tendência de 
comunicar a ideia de que elas são inteligentes, mas que conseguem sucesso quando se esforçam. Alguns exemplos foram: "eu sabia que você é capaz, se continuar se esforçando vou continuar tendo muito orgulho" / "com determinação sempre atingimos nossos objetivos. Parabéns" / "você é muito inteligente, mas tem preguiça". Com isso, os adultos parecem querer enfatizar para a criança que não é sua inteligência que está em jogo na dificuldade escolar, mas seu esforço.

Ademais, as diversas referências à desmotivação e falta de interesse também evidenciaram indícios dos sentidos e interpretações sobre o desempenho escolar e dos atributos valorizados pelos educadores. Essa tendência ficou ilustrada em frases como: "não sente interesse na leitura e escrita" / "falta de vontade de estudar" / "preguiça no aprendizado, não gosta de ler, aprender sobre as coisas, muito disperso. Só quer saber de brincar e copiar a lição e não quer aprender". Observaram-se alusões reiteradas ao prefixo "des" (que significa negação/privação): "desmotivação, desatenção, desorganização, despreocupação", referidas, inclusive, às questões cotidianas do lar: "dificuldade com a rotina (banho, escovar dentes, lição de casa)".

Além dos discursos, as práticas educativas também são interpretadas pelas crianças e ressoam no processo de autoconstrução valorativa do si mesmo. Diante da proposta de contar algo novo sobre si mesmo, Vin (M), de 9 anos que ainda não estava alfabetizado, comenta: "agora vou na classe de quem não sabe ler". Ele diz que mudou de escola para ir a uma classe "dos que não sabem ler", novidade que reflete a segregação de seu grupo para um contexto institucional de alunos tidos como "menos capazes" ou que "não sabem" e são rotulados no lugar do déficit.

Também referindo-se ao âmbito escolar surgem falas que refletem um tom pejorativo do juízo dos educadores na caracterização do próprio Eu. Em uma roda de conversa acerca do vínculo com os professores, $N(F)$ assinala o motivo de seu mal-estar: "as pessoas brigam comigo. As professoras falam que eu sou lenta". Nessa linha, o relatório psicopedagógico de Is (F) salienta que, segundo a mãe, a menina "tem se autorreferido como 'burra' e diz que não vai conseguir aprender mesmo". No mesmo documento, informa-se um coeficiente intelectual médio, mas déficit na atenção e memória.

Por último, nas descrições dos adultos acerca das crianças também identificou-se a perpetuação de estereótipos sexistas que, consciente ou inconscientemente, acabam sendo reforçados e valorizados pelos educadores no âmbito escolar e familiar. Esse fenômeno resulta exemplificado na escrita de uma mãe sobre os aspectos positivos de seus filhos (ambos participantes do programa de atendimento). Diz sobre o menino: "esforçado, dedicado aos esportes", e sobre a menina: "não se envolve em confusão, é carinhosa", diferença que parece estar permeada pela legitimação dos clichês do menino esportista e da menina dócil. 


\section{DISCUSSÃo}

A aprovação dos pares e o "fazer parte" de um grupo constituem fatores expansivos do desenvolvimento da criança escolar (Arbisio, 2007; Urribarri, 2012). Contudo, tal como observado nas falas dos participantes, os colegas não são unicamente fonte de confirmação e valorização narcisista, mas também de "zoação" e/ou provocações por características físicas e estéticas como peso, cor de pele ou por atributos como competências e habilidades. Em concordância com a literatura, evidenciou-se que, mesmo sem poder estabelecer relações de causa-consequência, as crianças com dificuldades na escola apresentam um autoconceito empobrecido, não só pelos resultados objetivos do seu desempenho acadêmico, mas especialmente pelo que os "outros" avaliam, acreditam e julgam.

Tanto no olhar dos educadores como dos pares, a dimensão de gênero é um dos elementos que permeia a construção da autovalorização. Os resultados deixam inferir modelos educativos de feminilidade (carinhosa, bonita) e masculinidade (esportista) que ressoam na constituição infantil das identidades de gênero (Reis \& Maia, 20019). Nesse sentido, as humilhações que mais parecem preocupar às meninas fizeram referência a ser "feia", o que pode ser relacionado com a cobrança social de responder a uma matriz estética de beleza (Arbisio, 2007). A tendência das crianças de 7 a 11 anos de demarcar diferenças de gênero na amizade, que leva a relações grupais que separam meninos de meninas, fortalece a divisão estereotipada da imposição de beleza feminina e de força física masculina (Urribarri, 2012). As autocobranças infantis sustentadas no sexismo se reforçam pela necessidade de autorrealização e satisfação na vida de grupo, ou seja, a vida similar para todos, baseada no "querer ser" como os outros (Arbisio, 2007).

Nos discursos dos educadores também foi sutilmente evidenciada a atual patologização da aprendizagem, ao assinalar aspectos valorizados nas suas concepções de estudo e disciplina, especialmente no modo de expressar o motivo de inscrição da criança (falta de atenção, esforço, interesse, etc). Pesquisas sobre a leitura meritocrática da aprendizagem vêm discutindo os impactos dos discursos que levam a individualizar o problema escolar na criança, oferecendo uma interpretação reducionista que a culpabiliza pelo seu desempenho e desresponsabiliza os educadores (Asbahr \& Lopes, 2006; Paula \& Tfouni, 2009). Tanto as explicações meritocráticas como as biologizantes em torno do fracasso escolar instalam-se no cotidiano de professores, familiares e até das próprias crianças (Garbarino, 2017; Ochoa \& Orbeta, 2017).

Além dos sentimentos de fracasso e sucesso derivados das experiências escolares, o olhar dos adultos é especialmente significativo na gênese da autovalorização durante a infância. Progressivamente, a criança constitui um narcisismo mais estável que não flutua na dependência dos juízos alheios sobre o si mesmo. É a aquisição da permanência do valor do Eu na impermanência dos 
vínculos. Portanto, nesse período, a debilidade do respeito mútuo (Piaget, 1954/2005), conquista característica do pensamento operatório infantil, leva a hostilidades corporizadas em insultos e julgamentos desvalorizantes que podem afetar significativamente a construção do autoconceito.

Destarte, tal como salientado em estudos anteriores (Muniz \& Fernandes, 2016), os resultados da pesquisa chamam a atenção para o papel do educador como mediador dos julgamentos alheios e co-construtor do autoconceito infantil, tanto quando investe o narcisismo da criança e oferece seu olhar configurador de um si mesmo capaz e potente, como quando intervém na direção contrária. Desde um modelo winnicottiano (Winnicott, 1993), a criança precisa de educadores "suficientemente bons" e de um apego inicial estruturante de autovalor para, progressivamente, poder se desapegar. Quando esse processo acontecer no nível da consciência de si mesmo, ela poderá se des-alienar do julgamento do outro a partir de um Eu mais equilibrado, sendo que, quanto maior a subjetividade, maior a objetividade (Piaget, 1975/2000). Em outras palavras, a maior tomada de consciência e conhecimento do si mesmo corresponde a um maior conhecimento do mundo extrapsíquico conformado por objetos e pessoas.

As valorizações dos educadores convergem na interface de dois grandes momentos do desenvolvimento infantil. Por um lado, a entrada na segunda infância que se corresponde com o que a psicanálise denomina como período de latência (Arbisio, 2007; Golse, 2009; Mijolla-Mellor, 2002; Urribarri, 2012) e, o que a psicologia genética chama de período operatório concreto (Piaget, 1954/2005). Por outro lado, é o momento da obrigatoriedade dos processos de escolarização e o início da alfabetização. Essa interface envolve a amplificação subjetiva do "ser filho", até então amado e valorizado a partir de cargas afetivas endogâmicas quase incondicionais. Se para ser "bom filho" bastava responder às demandas familiares, o ingresso na escola acrescenta novas exigências como moeda de troca desse amor filial. Assim, o "paraíso do amor evidente" (Mijolla-Mellor, 2002), que até então estruturava o vínculo com os objetos primários, complexifica-se no cenário escolar, com o olhar dos colegas e professores.

Dessa forma, no contexto da escolarização do ciclo Básico I, a autovalorização estará influenciada pelas expectativas parentais do "ser aluno" que será investido positiva ou negativamente segundo a qualidade do desempenho escolar. A progressiva construção do pensamento operatório traz ademais a queda das explicações mágicas e intuitivas do mundo (Piaget, 1924/1977; 1975/2000 Essa conquista, que fortalece a capacidade de duvidar do que se apresenta como natural e óbvio, gera impactos afetivos positivos, mas também não poucas angústias (Mijolla-Mellor, 2002). Em ambos os casos, os educadores funcionam como espelhos de autovalor.

A construção do conhecimento científico-escolar exige movimentos exogâmicos da cultura do familiar: a descentração do conhecido e do próximo e a desconstrução do aparente e do intuitivo das crenças. Por conta disso, a 
dificuldade escolar extrapola a questão da aprendizagem, comprometendo o desenvolvimento do sujeito e sua constituição psíquica. Toda conduta humana é, ao mesmo tempo, social e individual e o conhecimento científico nasce do confronto social, de compartilhar ideias que despencam ao contato com os outros (Piaget, 1924/1977). Essa fronteira entre o individual e o social também foi relativizada pela psicanálise, ao afirmar que a psicologia individual é ao mesmo tempo uma psicologia social porque "os outros" sempre atuam na vida mental como objetos, modelos, auxiliares ou oponentes (Freud, 1921/1996).

Os resultados aqui apresentados mostram que esses outros aparecem nas produções discursivas de um sujeito, de modo implícito ou explícito, seja como protagonistas de uma ação, como representantes de um discurso de saber ou autoridade, seja como bode expiatório das próprias frustrações. Inspirada em Paul Ricoeur, Schlemenson (2009) sublinha que, o que nos torna humanos é a capacidade de narrar a própria vida. Nessa perspectiva, o conceito de discurso narrativo define a produção dialética entre acontecimento e sentido, ou seja, uma trama de situações subjetivantes. Também Golse (2009) destaca o valor da clínica diacrônica-historizante baseada na narração subjetiva dos conflitos e sintomas, e assinala que essa abordagem não deveria ser considerado um luxo, mas uma necessidade humana do "ser de narração".

Nesse sentido, a respeito do dispositivo de rodas de conversa, cabe sublinhar que o convite à exposição pública de humilhações recebidas é uma tarefa delicada de aceitar, e a coragem de falar pode ser abordada a partir de vários prismas. Por um lado, é preciso lidar com a vergonha e os mecanismos de defesa, que estariam mais exacerbados nas crianças que dizem não ter sido zoadas ou que apelam a experiências alheias. Desde uma perspectiva psicanalítica, o período de latência caracteriza-se pela consolidação do Superego que envolve lidar com exigências de pais internalizados, a culpa, o Ideal do Eu, e os sentimentos de nojo e vergonha. Por sua vez, os mecanismos de defesa visam preservar a organização do Eu diante da multiplicidade de exigências do meio e as intrapsíquicas (Arbisio, 2007; Urribarri, 2012).

Por outro lado, sob uma perspectiva de intervenção clínica, a capacidade de falar abertamente sobre o tema evidenciaria a apropriação de uma oportunidade talvez atípica de denúncia de um mal-estar silencioso em um espaço de escuta pouco frequente nos contextos de naturalização da zoação como um "fazer parte" inevitável da experiência escolar. Destarte, as rodas de conversa permitem a abordagem de problemas de comportamento relacionados à dificuldade de aprendizagem. Nesse escopo, as temáticas tratadas variam conforme as necessidades e vivências de cada turma. No caso dos conflitos interpessoais, antes de começar as rodas é escolhido um problema concreto do cotidiano escolar, trazido por algum dos participantes. Posteriormente, é proposta uma reflexão dialógica, orientada pelos profissionais do atendimento, para discutir alternativas de resolução não agressivas que contemplem os sentimentos e pontos de vista próprios e alheios. 
Mas para além da psicologia clínica e do desenvolvimento, a psicologia social permite apontar ao fracasso escolar como uma "dimensão sócio-política do sofrimento" (Rosa, 2013) das crianças que encarnam esse fenômeno. Esse ângulo dialético da análise do sujeito na cultura complexifica a construção do autoconceito situando a dinâmica da criança com pares e educadores em um contexto histórico e sociopolítico de classificação de sujeitos. O prisma cultural dos atributos que se valorizam como positivos, tais como rapidez, beleza e sucesso, permeiam, irredutivelmente, a construção de uma autovalorização. Daí se desprende a importância das rodas de conversa como dispositivo na clínica da queixa escolar. Conforme aponta Voltolini (2001), a superação do mal-estar "tem a ver com um atravessamento questionador e responsável por esse sofrimento, ao contrário de petrificar-se nele" (p. 102). Desse modo, converter a demanda de atendimento da queixa em enigma acerca do sofrimento psíquico é uma das tarefas do profissional que pretende envolver criticamente o sujeito na sua aflição desconstruindo discursos cristalizados acerca da sua autoimagem.

\section{CONSIDERAÇÕES FINAIS}

Durante a infância o autoconceito se constrói majoritariamente na escola, palco de exposição infantil por excelência. Nele, o olhar do outro (que assume formas verbais ou gestuais, conscientes ou inconscientes) se traduz em uma apreciação, um investimento afetivo, uma valorização expansiva ou restritiva. Na perspectiva piagetiana, a capacidade de descentração cognitiva e afetiva, indicador da instauração dos limites Eu - não Eu, é progressivamente consolidada durante o período operatório, o que vai permitir não ficar alienado ao juízo do outro.

Em tempos de uma infância vulnerável ao bullying, ao fracasso escolar e à patologização, temáticas como a co-construção do autoconceito infantil resultam incontornáveis. Considerando as contribuições já elencadas da literatura, e diante dos resultados aqui apontados, salienta-se a necessidade de futuras pesquisas que afrontem esse desafio. Em termos metodológicos, o presente trabalho propõe as rodas de conversa como um dispositivo de pesquisa e intervenção favorável à tomada de consciência do autoconceito e dos sentimentos atrelados à autopercepção diante das apreciações alheias.

Problematizar e desconstruir a interpretação do outro, encarnado em elogios, insultos ou atributos qualificadores de educadores e pares envolve estabelecer uma distância simbólica entre o Eu - não Eu que desvie da alienação do sujeito ao mundo externo. Nesse processo, o olhar da alteridade (positivo ou negativo) pode ser transformado operatoriamente como juízo de valor de um outro diferente do Eu, para ser ou não internalizado, total ou parcialmente, como qualidade na representação do si mesmo. Cabe então ao educador gerar esse movimento em detrimento da repetição, da cristalização de rótulos e da estereotipia, promovendo uma dinâmica questionadora das tramas de significações das crianças acerca da queixa escolar e das suas modalidades de posicionamento diante do julgamento dos outros. 


\section{REFERÊNCIAS}

Alves, M. T. G., \& Soares, J. F. (2013). Contexto escolar e indicadores educacionais: Condições desiguais para a efetivação de uma política de avaliação educacional. Educação e Pesquisa, 39(1), 177-194. doi: 10.1590/S1517-97022013000100012

Antunes, M. E. S., \& Falcke, D. (2010). Contexto familiar e escolar de adolescentes com dificuldades de aprendizagem. Cadernos de Psicopedagogia, 8(14), 53-69.

Arbisio, C. (2007). L'enfant de la période de latence. Paris: Ed. Dunod.

Asbahr, F. S. F. \& Lopes, J. S. (2006). A culpa é sua. Psicologia USP, 17(1), 53-73.

Bordignon, N. A. (2007). O desenvolvimento psicossocial do jovem adulto em Erik Erikson. Revista Lasallista de Investigación, 4(2), 7-16.

Borlido, C. R., \& Martins, A. P. L. (2011). Perspectivas dos pais sobre dificuldades de aprendizagem específicas: Um inquérito por questionário realizado no norte de Portugal. Revista Brasileira de Educação Especial, 17(3), 363-372. doi: 10.1590/S1413-65382011000300002

Branco, P. I. \& Pan, M. A. G. S. (2016). Rodas de conversa: Uma intervenção da psicologia educacional no curso de medicina. Psicologia: Teoria e Prática, 18(3), 156-167. doi: 10.5935/1980-6906/psicologia.v18n3p156-167

Bzuneck, J. A. \& Sales, K. F. S. (2011). Atribuições interpessoais pelo professor e sua relação com emoções e motivação do aluno. Psico-USF, 16(3), 307-315. doi: 10.1590/S141382712011000300007

Cabanach, R. G. \& Arias, A. V. (1998). Características afectivo-motivacionales de los estudiantes con dificultades de aprendizaje. In V. Bermejo \& J. A. B. Llera (Eds.). Dificultades de aprendizaje. España: Editorial Síntesis, pp. 261-278.

Carneiro, G. R., Martinelli, S. C., \& Sisto, F. F. (2003). Autoconceito e dificuldades de aprendizagem na escrita. Psicologia: Reflexão e Crítica, 16(3), 427-434. doi: 10.1590/S0102 79722003000300002

Castro, T. G., Abs, D., \& Sarriera, J. C. (2011). Análise de conteúdo em pesquisas de Psicologia. Psicologia: Ciência e Profissão, 31(4), 814-825. doi: 10.1590/S1414-98932011000400011

Fialho, L. M., Santana, J. R., \& Brandenburg, C. (2015). La calidad de vida infantil y sus dimensiones: Percepción de escolares. Barbarói, 45, 227-241. doi: 10.17058/barbaroi.v0i0.5065

Freud, S. (1996). Psicologia de grupo e análise do ego. In S. Freud, Edição standard brasileira das obras psicológicas completas de Sigmund Freud (J. Salomão, trad., vol. 23, pp. 79-159). Rio de Janeiro, RJ: Imago. (Trabalho original publicado em 1921).

Garbarino, M. I. (2017) Construção do prazer de pensar e desenvolvimento: Um estudo teórico-clínico com crianças em dificuldade escolar. (Tese de Doutorado). Universidade de São Paulo, São Paulo.

Golse, B. (2009). Le développement affectif et intellectuel de l'enfant. Paris: Médecine et Psychothérapie.

Gutton, P. (2009). Le jeu chez l'enfant. Paris: Larousse. (Trabalho original publicado em 1973).

Jacob, A. Loureiro, S. R., Marturano, E. M., Linhares, M. B. M., \& Machado, V. L. S. (1999). Aspectos afetivos e o desempenho acadêmico de escolares. Psicologia: Teoria e Pesquisa, 15(2), 153 162. doi: 10.1590/S0102-37721999000200008

Macedo, L., Petty, A. L., \& Passos, N. C. (2005). Os jogos e o lúdico na aprendizagem escolar. Porto Alegre, Rs: Artmed.

Mazer, S. M., Bello, A. C. D., \& Bazon, M. R. (2009). Dificuldades de aprendizagem: Revisão de literatura sobre os fatores de risco associados. Psicologia da Educação, (28), 7-21.

Melo, R. H. V., Felipe, M. C. P, Cunha, A. T. R., Vilar, R. L. A., ... , Diniz Júnior, J. (2016). Roda de conversa: Uma articulação solidária entre ensino, serviço e comunidade. Revista Brasileira de Educação Médica, 40(2), 301-309. doi: 10.1590/1981-52712015v40n2e01692014

Mijolla-Mellor, S. (2006). Le plaisir de pensée (Une lecture de l'ouvre de Piera Aulagnier). Paris: PUF.

Monteiro, V. (2012). Promoção do autoconceito e autoestima através de um programa de leitura a par. Psicologia: Reflexão e Crítica, 25(1), 147-155. doi: 10.1590/S0102-79722012000100018

Muniz, M., \& Fernandes, D. C. (2016). Autoconceito e ansiedade escolar: Um estudo com alunos do ensino fundamental. Psicologia Escolar e Educacional, 20(3), 427-436. doi: 10.1590/21753539/2015/0203874

Ochoa, M. P. \& Orbeta, C. T. (2017). Discursos sobre clase social y meritocracia de escolares vulnerables en Chile. Cadernos de Pesquisa, 47(164), 496-518. doi: 10.1590/198053143752 
Osti, A. \& Brenelli, R. (2013). Sentimentos de quem fracassa na escola: Análise das representações de alunos com dificuldades de aprendizagem. Psico-USF, 18(3), 417-426. doi: 10.1590/S1413-82712013000300008

Paín, S. (2010). Diagnóstico y tratamiento de los problemas de aprendizaje. Buenos Aires: Nueva Visión.

Patto, M. H. S. (1997). Para uma Crítica da Razão Psicométrica. Psicologia USP, 8(1). doi: 10.1590/S0103-65641997000100004

Paula, F. S. \& Tfouni, L. V. (2009). A persistência do fracasso escolar: Desigualdade e ideologia. Revista Brasileira de Orientação Profissional, 10(2), 117-127.

Piaget, J. (1977). O raciocínio na criança. Rio de Janeiro, RJ: Record. (Trabalho original publicado em 1924).

Piaget, J. (2000). La equilibración de las estruturas cognitivas. Problema central del desarrollo. México: Siglo XXI. (Obra original publicada em 1975).

Piaget, J. (2005). Inteligencia y afectividad. Buenos Aires: Aique. (Trabalho original publicado em 1954).

Polydoro S., \& Azzi, G. R. (2008). Auto-regulação: Aspectos introdutórios. In A. Bandura, R. G. Azzi, \& S. Polydoro, Teoria social cognitiva: Conceitos básicos. Porto Alegre, RS: Artmed

Ribeiro, M. L. (2010). A afetividade na relação educativa. Estudos de Psicologia (Campinas), 27(3), 403-412. doi: 10.1590/S0103-166X2010000300012

Rosa, M. D. (2013) Imigração Forçada: A dimensão sócio-política do sofrimento e a transmissão da história. In M. D. Rosa, T. T. Carignato, \& S. L. S. Alencar (Eds.), Desejo e política: Desafios e perspectivas no campo da imigração e refúgio. São Paulo, SP: Max Limonad.

Rosenthal, G. (1974). El período de latencia. Revista de Psicoanálisis da Asociación Psicoanalítica Argentina, XXXII.

Sabina R., B., Saéz, Z., \& Roméu E., M. (2010). Factores de riesgo asociados a transtornos en el aprendizaje escolar: Un problema sociomédico. MediSur, 8(4), 30-39.

Sadalla, A. M. F. A. (1998). Com a palavra a professora: Suas crenças, suas ações. Campinas, SP: Editora Alínea

Sampaio, J., Santos, G. C., Agostini, M., \& Salvador, A. S. (2014). Limites e potencialidades das rodas de conversa no cuidado em saúde: Uma experiência com jovens no sertão pernambucano. Interface, 18(2), 1299-1311. doi: 10.1590/1807-57622013.0264

Santos, C. C., \& Ortega, A. C. (2012). Relações entre aspectos cognitivos e afetivos em idosas. SCHEME, Revista Eletrônica de psicologia e epistemologia genéticas, 4(1), 109-148.

Schlemenson, S. (2009). La clínica en el tratamiento psicopedagógico. Buenos Aires: Editorial Paidós.

Shure, M. B. (2006). Eu posso resolver problemas. Educação infantil e ensino fundamental: um programa de solução cognitiva para problemas interpessoais. Petrópolis, RJ: Vozes

Sisto, F., \& Martinelli, S. (Eds.) (2006). Afetividade e dificuldades de aprendizagem: Uma abordagem psicopedagógica. São Paulo, SP: Vetor.

Souza, A. S. L. (2014). Re-visitando a latência: Reflexões teórico-clínicas sobre os caminhos da sexualidade. Psicologia USP, 25(2), 155-161. doi: 10.1590/0103-656420130003

Steibel D., Hallberg A. E., Sanchotene, B., Campezatto P. V. M., Silva M. R., \& Nunes M. L. T. (2011). A latência na atualidade: Considerações sobre crianças encaminhadas para psicoterapia. Aletheia, (35-36), 51-68.

Stevanato, I., Siqueira, L., Sonia R., Linhares, M. B. M., \& Marturano, E. M. (2003). Autoconceito de crianças com dificuldades de aprendizagem e problemas de comportamento. Psicologia em Estudo, 8(1), 67-76. doi: 10.1590/S1413-73722003000100009

Urribarri, R. (2012). Estruturação psíquica e subjetivação da criança em idade escolar. São Paulo, SP: Escuta.

Voltolini, R. (2001). Do contrato pedagógico ao ato analítico: Contribuições à discussão da questão do mal-estar na educação. Estilos da Clínica, 6(10), 101-111.

Winnicott, D. (1993). El análisis del niño en el período de latencia. In D. Winnicott, Los procesos de maduración y el ambiente facilitador (pp. 149-160). Buenos Aires: Paidós.

Zequinão, M. A., Medeiros, P., Pereira, B., \& Cardoso, F. L. (2016). Association between spectator and other roles in school bullying. Journal of Human Growth and Development, 26(3), 352-359. doi: 10.7322/jhgd.122819 


\section{AGRADECIMENTOS}

A autora agradece à CAPES pelo financiamento da pesquisa por concessão de bolsa de doutorado.

\section{CONFLITOS DE INTERESSES}

Não há conflitos de interesses.

\section{SOBRE A AUTORA}

Mariana Inés Garbarino é psicóloga pela Universidade de Buenos Aires, mestre e doutora em Psicologia Escolar e do Desenvolvimento Humano pela Universidade de São Paulo. Professora substituta no curso de Pedagogia na Universidade Federal de São Paulo (Unifesp), Campus Guarulhos. e-mail: marianagarbarino@usp.br 